\title{
Antioxidants in eggs of great tits Parus major from Chernobyl and hatching success
}

\author{
Anders Pape Møller · Filis Karadas • \\ Timothy A. Mousseau
}

Received: 28 October 2007 / Revised: 17 March 2008 / Accepted: 19 March 2008 / Published online: 8 April 2008

(C) Springer-Verlag 2008

\begin{abstract}
Antioxidants are powerful protectors against the damaging effects of free radicals that constitute the inevitable by-products of aerobic metabolism. Growing embryos are particularly susceptible to the damaging effects of free radicals produced during rapid growth, and mothers of many species provide protection against such damage by allocating antioxidants to their eggs. Birds living in radioactively contaminated areas use dietary antioxidants to cope with the damaging effects of radiation, but females also allocate dietary antioxidants to eggs, potentially enforcing a physiological trade-off between self-maintenance and reproductive investment. Here we tested whether female great tits Parus major breeding in radioactively contaminated study areas near Chernobyl allocated less dietary antioxidants to eggs, and whether such reduced allocation of dietary antioxidants to eggs had fitness consequences. Concentrations of total yolk carotenoids and vitamins A and $\mathrm{E}$ were depressed near Chernobyl compared to concentrations in a less contaminated Ukrainian study area and a French control study area, and all antioxidants showed dose-dependent relationships with all three dietary antioxi-
\end{abstract}

Communicated by G. Heldmaier.

A. P. Møller $(\bowtie)$

Laboratoire de Parasitologie Evolutive, CNRS UMR 7103,

Université Pierre et Marie Curie, Bât. A, 7ème étage,

7 quai St. Bernard, Case 237, 75252 Paris Cedex 05, France

e-mail: amoller@snv.jussieu.fr

F. Karadas

Department of Animal Science,

University of Yüzüncü Yil, Van, Turkey

T. A. Mousseau

Department of Biological Sciences,

University of South Carolina, Columbia, SC 29208, USA dants decreasing with increasing level of radiation at nest boxes. These effects held even when controlling statistically for potentially confounding habitat variables and covariation among antioxidants. Laying date was advanced and clutch size increased at nest boxes with high dose rates. Hatching success increased with increasing concentration of vitamin E, implying that hatching success decreased at boxes with high levels of radiation, eventually eliminating and even reversing the higher potential reproductive output associated with early reproduction and large clutch size. These findings are consistent with the hypothesis that radioactive contamination reduced levels of dietary antioxidants in yolks, with negative consequences for hatching success and reproductive success.

Keywords Antioxidants · Clutch size - Dose rate · Hatching success $\cdot$ Laying date

\section{Introduction}

Aerobic metabolism produces energy at a cost of production of free radicals that are highly reactive biochemical agents (e.g. Halliwell and Gutteridge 1999; Leffler 1993). Free radicals are a natural outcome of aerobic metabolism, with mitochondrial metabolism producing free radicals that if uncontrolled can damage DNA and other molecules (e.g. Halliwell and Gutteridge 1999; Leffler 1993). Such damage has to be repaired or it will have somatic consequences for self-maintenance or germline consequences by inducing deleterious mutations that can be transmitted to the next generation. Anti-oxidants such as vitamins A and E, carotenoids and several others are either synthesized or ingested as a means of reducing oxidative stress (e.g. Møller et al. 2000; Surai 2002). Females of many animals provision 
their offspring with antioxidants as a means of reducing the negative effects of free radicals during embryonic and postnatal growth, causing antioxidants to be a unique suite of maternal effects with potential trans-generational effects on offspring performance (Mousseau and Fox 1998). Birds are (together with bats) unique among animals in having extremely high metabolic rates (and therefore high rates of production of free radicals), relatively high rates of adult survival for their body size and low rates of senescence (Holmes et al. 2001). In addition, birds are responsible for some of the most remarkable bi-annual migrations, with the record being held by Arctic terns Sterna paradisaea that migrate up to $44,000 \mathrm{~km}$ per year and up to more than one million kilometers in lifetime (the longevity record for that species is a remarkable 32 years, Berthold 2001). The combination of these facts suggests that birds have evolved a range of physiological mechanisms that allow them to successfully cope with high levels of oxidative stress. In fact, low production of free radicals per unit of oxygen consumption by mitochondria may explain these effects (Barja et al. 1994).

There has been increasing recent interest in ecological and evolutionary effects of free radicals and antioxidants. These recent studies include experiments designed to manipulate the antioxidant status of mothers or offspring with the objective of elucidating effects on performance or fitness (e.g. Saino et al. 2003; Biard et al. 2007; Costantini et al. 2007). A second approach has been to manipulate the workload of animals and subsequently investigate effects on free radical load and antioxidant status (e.g. AlonsoAlvarez et al. 2004). Yet another approach has been to investigate natural variation in free radical load and antioxidant status, under the assumption that natural variation must have fitness consequences if free radicals and antioxidants play significant proximate roles in optimizing fitness (e.g. Costantini et al. 2006).

Radioactively contaminated areas may constitute a previously under-exploited model system for studies of the effects of antioxidants and free radicals and their effects on individual performance and fitness. Both humans and birds living in radioactively contaminated areas suffer physiological consequences in terms of reduced levels of dietary antioxidants because a higher load of free radicals depletes the amounts of circulating and stored antioxidants (Chaialo et al. 1991; Bazhan 1998; Ben-Amotz et al. 1998; Ivaniota et al. 1998; Neyfakh et al. 1998a, b; Lykholat and Chernaya 1999; Kumerova et al. 2000; Møller et al. 2005b). Such reductions in levels of circulating and stored antioxidants can have important consequences for reproductive decisions, including whether or not to reproduce (up to a quarter of females not reproducing in areas with high levels of radiation), clutch size (fewer eggs being produced in areas with high levels of radiation) and antioxidant investment in eggs (reduced amounts of dietary antioxidants allocated by female birds to eggs in areas with high levels of radiation, Møller et al. 2005a). Møller et al. (2005b) analyzed antioxidant levels in barn swallows Hirundo rustica around Chernobyl in relation to local levels of background radiation, and found that circulating concentrations of dietary total carotenoids and vitamins $\mathrm{A}$ and $\mathrm{E}$ in blood, stores of these three dietary antioxidants in liver and concentrations in egg yolk were severely depressed compared to control areas. These reduced concentrations of dietary antioxidants predicted levels of abnormal sperm that increased from less than $5 \%$ in areas with high levels of antioxidants to more than $40 \%$ in areas with the lowest levels of antioxidants (Møller et al. 2005b). These findings are consistent with the hypothesis that mutations as reflected by abnormal sperm morphology increase in the absence of antioxidants.

The objective of this study was to investigate how egg quality in terms of antioxidants was related to background radiation level in a study area in the highly contaminated Red Forest, Ukraine, a weakly contaminated study area near Izumrudnoe, Ukraine, and an uncontaminated control study area in France. The second objective was to investigate the fitness consequences of antioxidant levels in yolks. This was done using great tits Parus major breeding in nest boxes as a model system. Because availability of antioxidants may depend on habitat features, we described habitats surrounding nest boxes in detail and included these habitat features as predictor variables in our models. Previous studies of great tits in contaminated study areas in Ukraine have shown that tits avoid breeding in the most contaminated study areas, despite the fact that there is little evidence of reduced reproductive success in these study areas (Møller and Mousseau 2007a). A comparative study of interspecific differences in the response of birds to radioactivity around Chernobyl revealed that species with carotenoid-based plumage coloration, long migration distance, long dispersal distance, and heavy eggs (all traits closely associated with higher levels of use of antioxidants) all independently predicted decrease in population density with increasing levels of background radiation (Møller and Mousseau 2007b). Therefore, these studies suggest that antioxidant levels play an important role in the response of birds to radioactive contamination.

\section{Materials and methods}

Study areas

S. Gaschak, APM and TAM investigated nest boxes in a study area in the Red Forest, Ukraine, where radioactive contamination reaches levels greater than 2,000 times the natural background level, in a contaminated study area in 
Izumrudnoe, Ukraine, with levels around 100 times normal background radiation levels, and in a second control study area in Foret d'Orient, France. In 2002-2003 we erected 232 nest boxes of a standard size $(20 \times 20 \times 40 \mathrm{~cm})$ with a $32 \mathrm{~mm}$ diameter hole in the Ukrainian study areas. All the boxes were placed at a distance of at least $50 \mathrm{~m}$ between boxes, and they were located at a height of 1.5-2.0 m. High levels of spatial heterogeneity in radiation levels (Shestopalov 1996) provided an ideal setting for investigating the relationship between reproduction and radiation, making it unlikely that results would be confounded by spatial autocorrelation in food abundance, habitat, or other features. Thus, high heterogeneity in levels of radiation is unlikely to exactly match high heterogeneity in food abundance, habitat, or other features. Møller and Mousseau (2007a) provide a map showing this high degree of spatial heterogeneity in levels of background radiation.

The habitat surrounding nest boxes was forest with a mixture of deciduous and coniferous trees and shrubs, and the oldest trees were less than 100 years old. We classified habitats surrounding each box along four different axes: (1) Habitat [(a) birch Betula sp., (b) birch with aspen Populus sp. and alder Alnus sp., (c) pine Pinus sp.]. (2) Age of stands [(a) young trees without natural holes, (b) older trees with natural holes]. (3) Undergrowth [(a) absent, (b) sparse, (c) dense)]. (4) Habitat humidity [(a) dry, (b) humid, (c) wet with open water]. We analyzed one egg from each of 45 nests of great tits from 2003 to 2005 from the Red Forest and 26 nests from 2006 from Izumrudnoe.

A control study area in Foret d'Orient, France $\left(48^{\circ} 17^{\prime} \mathrm{N}, 4^{\circ} 18^{\prime} \mathrm{E}\right.$, Biard 2004; Biard et al. 2006) (about 250 ha) contained 400 nest boxes evenly distributed among homogenous deciduous old woodland composed mainly of oak (Quercus spp.), hornbeam (Carpinus betulus) and beech (Fagus sylvatica). We analyzed one egg from each of 42 nests of great tits from 2003 to 2004 from this study area.

\section{Recording nest box contents}

We visited nest boxes during April-May, 2003-2006 to check for occupancy, identifying species from adults, eggs and nests present. We estimated laying date from the presence of clutches that had not been completed, assuming that one egg was laid per day (Cramp and Perrins 1988-1993). Likewise, we used the age of nestlings to estimate date of laying of the first egg, assuming an incubation period of 13.9 days and a nestling period of 18.9 days (Cramp and Perrins 1988-1993).

Clutch size was estimated as the number of eggs in completed clutches, and brood size as the number of young in the nest after hatching, but before fledging. Hatching success was defined as brood size at hatching divided by clutch size, and fledging success as brood size at fledging divided by brood size at hatching.

\section{Recording background radiation levels at nest boxes}

As an estimate of background radiation levels we relied on a dataset of air-gamma-survey of the Chernobyl Exclusion Zone, including geo-positioned data of ${ }^{137} \mathrm{Cs}$ and ${ }^{90} \mathrm{Sr}$ deposition in a grid of $100 \times 100 \mathrm{~m}$ as of 1 January 1992. Using corresponding software (MapInfo Prof.) we sampled from the database all the data that were within a radius of $500 \mathrm{~m}$ from each nest box. The choice of a radius of $500 \mathrm{~m}$ was based on the assumption that most birds remained within an area with a radius of $500 \mathrm{~m}$ during breeding as suggested by the size of the home range of tits during breeding (Perrins 1979). Radioactive isotopes decay at a characteristic rate, implying that the radiation data from 1992 should be higher than, but positively correlated with the data from 2006. We cross-validated these data from 1992 using our own field measurements of background radiation at the ground level using a hand-held Inspector (Model: Inspector, SE International, Inc., Summertown, TN, USA) dosimeter at a sample of 28 nest boxes during May-June 2006. As expected, there was a strong positive relationship between these two series of measurements $[F=210.99$, d.f. $=1,26, r^{2}=0.89, P<0.0001$, slope $\left.(\mathrm{SE})=1.15(0.08)\right]$ (Møller and Mousseau 2007a).

Antioxidant analyses

We have shown previously that if the concentrations of total carotenoids and vitamins $\mathrm{A}$ and $\mathrm{E}$ in yolks of one egg are at a specific level, they are at a similar level in subsequent eggs produced by the same female (Biard 2004). All the antioxidant analyses were done by FK blindly with respect to the origin of nests and hence the level of background radiation. Eggs were separated into egg white and yolk, and the egg white was used for other analyses, while the yolk was used for androgen and antioxidant analyses. Entire eggs were frozen as soon as possible after collection, and then maintained at $-20^{\circ} \mathrm{C}$ until analysis in 2006 . All the samples from the same area were stored for the same period of time, eliminating the possibility that storage under oxygen could have produced the differences reported here. Antioxidants were extracted from 0.1 to $0.2 \mathrm{~g}$ of yolk. Samples were homogenized with $0.7 \mathrm{ml} \mathrm{NaCl}(5 \%)$ and $1 \mathrm{ml}$ ethanol, after which we added $2 \mathrm{ml}$ hexane followed by further homogenization, centrifugation and collection of the hexane phase (extraction repeated twice). Hexane extracts were pooled and evaporated at $60-65^{\circ} \mathrm{C}$ under nitrogen flow, and the residue was dissolved in dichloromethane and methanol (v:v). Carotenoid and vitamins A and E concentrations were determined following previously 
published procedures (Surai 2000; Hõrak et al. 2002). Total carotenoid concentration was determined by HPLC with a Spherisorb type $\mathrm{S} \mathrm{NH}_{2}$ normal-phase column $25 \mathrm{~cm} \times 4.6 \mathrm{~mm}$ (Phase separation, Clwyd, UK) with a mobile phase of methanol-distilled water (97:3), at a flow rate of $1.5 \mathrm{ml} / \mathrm{min}$. Lutein was used for calibration (Sigma, Poole, UK). Concentrations of vitamins $\mathrm{A}$ and $\mathrm{E}$ were determined by injection of samples onto a Spherisorb type ODS2 $3-\mu$ C18 reverse-phase column, $15 \mathrm{~cm} \times 4.6 \mathrm{~mm}$ (Phase Separation, Clwyd, UK) with a mobile phase of methanol/distilled water (97:3), at a flow rate of $1.05 \mathrm{ml} /$ min using fluorescence detection by excitation and emission wavelength of 295 and $330 \mathrm{~nm}$, respectively, for vita$\min \mathrm{E}$ and 330 and $480 \mathrm{~nm}$ for vitamin A. Peaks of retinol, $\delta$-, $\gamma$ - and $\alpha$-tocopherol were identified by comparison with the retention time of standards (Sigma, Poole, UK). All the sampled yolks were analyzed for total carotenoids, vitamins $\mathrm{A}$ and $\mathrm{E}$ concentrations. Vitamin $\mathrm{E}$ was calculated as the summed concentrations of $\delta$-, $\gamma$ - and $\alpha$-tocopherol. Concentrations rather than quantities of antioxidants were used as the variable of interest in statistical analysis because concentration is the main factor determining physiological action of antioxidants at the level of developing tissues that are subject to damage caused by free radicals (Surai 2002). The inter-assay CVs for retinol and alphatocopherol determinations were 3.9 and $4.4 \%$ respectively (Surai 2000).

\section{Statistical analyses}

We used the French control study area only in an analysis of variation in antioxidant levels among study areas, but excluded this study area from the analyses of effects of radiation and fitness consequences because radiation level never reached more than the common background radiation level in the French study area.

Hatching success and fledging success were square-root arcsine-transformed, while dose rate was log-transformed to meet requirements for normally distributed data.
We modeled antioxidant levels in relation to log-transformed dose rate of boxes, using Generalized Linear Models. These models included study area and year as factors.

We modeled laying date, clutch size, hatching success and fledging success by using study area, year, dose rate, antioxidant levels and four habitat variables (main tree species, age of stands, undergrowth, habitat humidity) as predictor variables. Habitat was used as a factor, while the three other habitat variables were used as continuous variables. In addition, because clutch size may depend on laying date, we included laying date and its interaction with dose rate in the analyses. For hatching and fledging success we included laying date, clutch size, year and study area as additional variables.

Data were missing for some variables due to complete nest failure, causing sample sizes to differ among tests. Variables reported are means (SE).

\section{Results}

Antioxidant levels in yolks differed significantly among the three study areas, with reduced levels in the Red Forest and to some extent in Izumrudnoe compared to the uncontaminated study area in France (Table 1). While total carotenoid levels in the Red Forest were $62 \%$ of the level in France, and the level of vitamin A was 59\%, the level of vitamin E was only $11 \%$ (Table 1 ). These patterns could potentially be due to differences among study areas caused by many different factors. Therefore, we investigated patterns within the two Ukrainian study areas by including study area as a factor.

Antioxidant levels in yolks decreased with increasing dose rate at nest boxes for all three antioxidants in analyses of data from the Red Forest and Izumrudnoe (Fig. 1). This effect was independent of potentially confounding variables such as year, habitat and study area (Table 2). Likewise, there was a similar negative relationship within the data set from the Red Forest $\left(F>4.43\right.$, d.f. $=1,43, r^{2}>0.08$,

Table 1 Mean $(\mathrm{SE})$ concentration $(\mu \mathrm{g} / \mathrm{g})$ of antioxidants in yolks of great tits from Red Forest, Izumrudnoe (Ukrainian control study area) and France (external control study area)

\begin{tabular}{lllll}
\hline Variable & Red Forest & Izumrudnoe & France & $\begin{array}{l}\text { Relative concentration } \\
\text { in Red Forest }\end{array}$ \\
\hline Total carotenoids $(\mu \mathrm{g} / \mathrm{g})$ & $15.49(1.07)^{\mathrm{a}}$ & $25.76(2.33)^{\mathrm{b}}$ & $25.93(1.90)^{\mathrm{b}}$ & 0.60 \\
Vitamin A $(\mu \mathrm{g} / \mathrm{g})$ & $1.69(0.13)^{\mathrm{a}}$ & $2.12(0.19)^{\mathrm{b}}$ & $2.88(0.18)^{\mathrm{c}}$ & 0.59 \\
Total vitamin E $(\mu \mathrm{g} / \mathrm{g})$ & $15.49(1.07)^{\mathrm{a}}$ & $25.76(2.33)^{\mathrm{b}}$ & $137.08(8.58)^{\mathrm{c}}$ & 0.11 \\
$N$ & 45 & 26 & 42 & \\
\hline
\end{tabular}

The relative concentration in Red Forest was the mean concentration in Red Forest relative to France. Differences among the three study areas were significant (total carotenoids: $F=14.58, d . f .=2,110, r^{2}=0.21, P<0.0001$; vitamin A: $F=13.05, d . f .=2,110, r^{2}=0.20, P<0.0001$; vitamin E: $F=33.42$, d.f. $\left.=2,110, r^{2}=0.38, P<0.0001\right)$. Means with different superscripts differed significantly $(P<0.05)$ from each other in Scheffe $F$ tests 

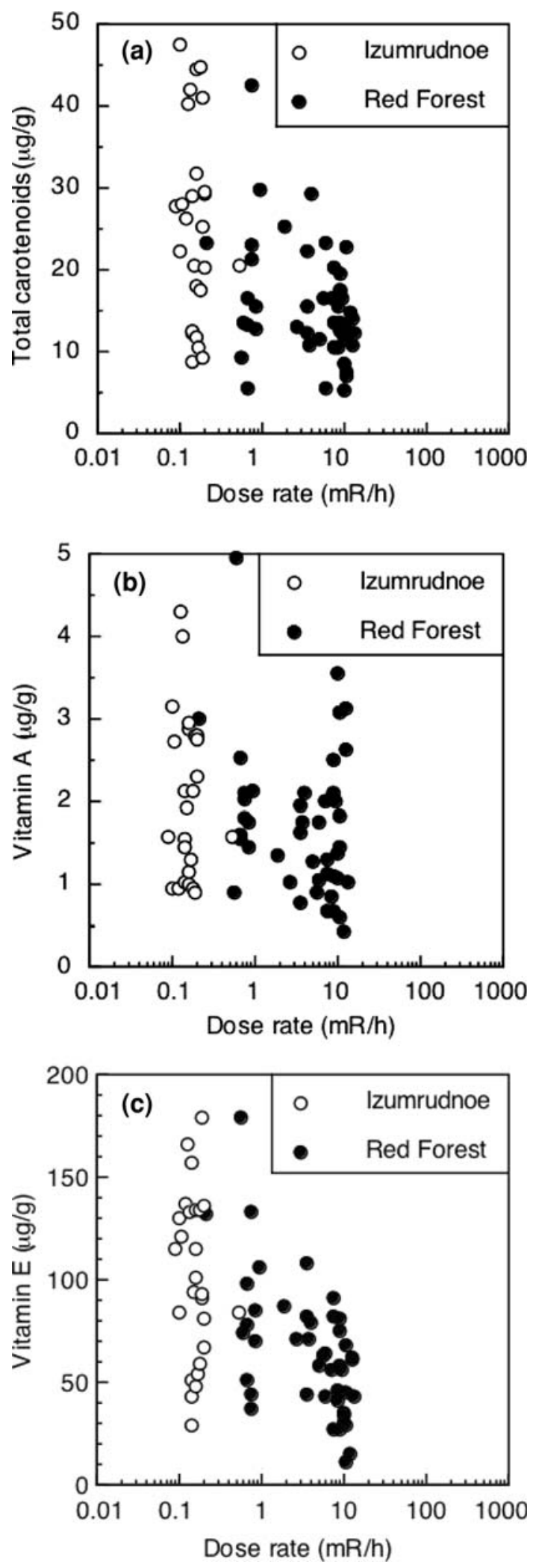

Fig. 1 Concentration of antioxidants $(\mu \mathrm{g} / \mathrm{g})$ in yolks of great tits in relation to dose rates for nest boxes $(\mathrm{mR} / \mathrm{h})$. a Total carotenoids, $\mathbf{b}$ vitamin $\mathrm{A}$ and $\mathbf{c}$ vitamin $\mathrm{E}$
Table 2 Antioxidant levels in yolks of great tits in relation to year, dose rate, habitat features and study area

\begin{tabular}{llrllr}
\hline Variable & $\begin{array}{l}\text { Sum of } \\
\text { squares }\end{array}$ & d.f. & $F$ & $P$ & Slope (SE) \\
\hline Total carotenoids & & & & & \\
Vitamin E & 0.28 & 1 & 7.51 & 0.0078 & $0.31(0.11)$ \\
Dose rate & 0.22 & 1 & 5.73 & 0.019 & $-0.09(0.04)$ \\
Error & 2.56 & 68 & & & \\
Vitamin A & & & & & \\
Dose rate & 0.25 & 1 & 5.49 & 0.022 & $-0.08(0.03)$ \\
Error & 3.17 & 69 & & & \\
Vitamin E & & & & & \\
Vitamin A & 0.30 & 1 & 8.56 & 0.0047 & $0.31(0.11)$ \\
Total carotenoids & 0.17 & 1 & 4.96 & 0.029 & $0.25(0.11)$ \\
Dose rate & 0.46 & 1 & 13.43 & 0.0005 & $-0.12(0.03)$ \\
Error & 2.31 & 67 & & & \\
\hline Year, habitat and & & & & & \\
\hline
\end{tabular}

Year, habitat and study area never entered as predictors. Antioxidant levels and dose rates were $\log _{10}$-transformed before analysis. The relationships between antioxidant levels and dose rates are shown in Fig. 1. The reported models had the statistics $F=15.32$, d.f. $=2,68, r^{2}=0.31$, $P<0.0001, F=5.49$, d.f. $=1,69, r^{2}=0.07, P=0.022$ and $F=19.03$, d.f. $=3,67, r^{2}=0.46, P<0.0001$

$P<0.045)$, and analyses of the data using Kendall rankorder correlations provided a similar conclusion (Kendall $\tau<-0.22, P<0.037)$.

Laying date differed significantly between the two study areas $[F=17.31$, d.f. $=1,117, P<0.0001$; Red Forest: 3 May $(\mathrm{SE}=1), N=82$; Izumrudnoe: 14 May $(\mathrm{SE}=3)$, $N=37]$. Laying date advanced with dose rate, independent of year, habitat and study area (Table 3; Fig. 2a). Clutch size differed significantly between the two study areas $[F=10.56$, d.f. $=1,477, P=0.0014 ;$ Red Forest: 9.08 $(\mathrm{SE}=0.31), \quad N=104 ; \quad$ Izumrudnoe: $7.36 \quad(\mathrm{SE}=0.38)$, $N=104]$. Clutch size increased with dose rate at nest boxes, independent of date of egg laying, year, habitat and study area (Table 3; Fig. 2b). Brood size at hatching differed marginally between the two study areas $[F=3.86$, d.f. $=1,116, P=0.052$; Red Forest: $6.96(\mathrm{SE}=0.49$ ), $N=75$; Izumrudnoe: $5.49(\mathrm{SE}=0.51), N=43$ ]. Brood size at fledging did not differ significantly between the two study areas $[F=0.57$, d.f. $=1,104, P=0.45$; Red Forest: $4.88(\mathrm{SE}=0.55), N=66$; Izumrudnoe: $5.50(\mathrm{SE}=0.54)$, $N=40]$. Hatching success increased with increasing concentration of vitamin $\mathrm{E}$ in yolks, independent of date of egg laying, year, habitat and study area (Fig. 3), while there was no significant effect for fledging success, independent of date of egg laying, year, habitat and study area (partial effect of dose rate: $F=0.01, d . f .=1,71, P=0.92$ ). The positive relationship between hatching success and concentration of vitamin $\mathrm{E}$ was confirmed in a non-parametric 
Table 3 Laying date and clutch size in relation to concentration of antioxidants in yolks, dose rate, habitat features, study area and year

\begin{tabular}{lrrrrr}
\hline Variable & $\begin{array}{l}\text { Sum of } \\
\text { squares }\end{array}$ & d.f. & \multicolumn{1}{l}{$F$} & $P$ & Slope (SE) \\
\hline Laying date & & & & & \\
Clutch size & 5928.32 & 1 & 63.47 & $<0.0001$ & $-2.86(0.36)$ \\
Dose rate & 344.65 & 1 & 3.69 & 0.057 & $-3.03(1.58)$ \\
Error & 10834.05 & 116 & & & \\
Clutch size & & & & & \\
Laying date & 256.19 & 1 & 63.47 & $<0.0001$ & $-0.12(0.02)$ \\
Dose rate & 55.62 & 1 & 13.78 & 0.0003 & $1.17(0.31)$ \\
Error & 468.19 & 116 & & & \\
\hline
\end{tabular}

Study area never entered as a predictor. The reported models had the statistics $F=59.48$, d.f. $=2,116, r^{2}=0.51, P<0.0001$ and $F=69.39$, d.f. $=2,116, r^{2}=0.54, P<0.0001$

Kendall rank-order correlation analysis (Kendall $\tau=0.21$, $P=0.021)$. Restricting these analyses to the data from the Red Forest only provided a similar conclusion $[F=6.09$, d.f. $=1,35, \quad r^{2}=0.15, \quad P=0.019, \quad$ slope $\quad(\mathrm{SE})=0.687$ (0.279); Kendall rank-order correlation analysis: Kendall $\tau=0.24, P=0.040]$.

\section{Discussion}

The main findings of this study of antioxidants in yolks of a resident passerine bird were (1) antioxidant concentration differed among populations, with severely depressed levels in the Red Forest near Chernobyl, (2) these effects showed dose-dependent negative relationships, and (3) fecundity was positively related to dose rate, while hatching success was negatively related to concentration of vitamin $\mathrm{E}$ in yolks. We will briefly discuss these findings and their implications.

Antioxidant levels have been shown to decrease in response to exposure to radiation in both humans and birds (Chaialo et al. 1991; Bazhan 1998; Ben-Amotz et al. 1998; Ivaniota et al. 1998; Neyfakh et al. 1998a, b; Lykholat and Chernaya 1999; Kumerova et al. 2000; Møller et al. $2005 \mathrm{~b}$ ). While some of these studies show an effect of radiation exposure on levels of antioxidants (Chaialo et al. 1991; Bazhan 1998; Ben-Amotz et al. 1998; Ivaniota et al. 1998; Lykholat and Chernaya 1999; Kumerova et al. 2000; Møller et al. 2005b), others have shown that mothers that had been exposed to radiation produce offspring with antioxidant deficiencies (Neyfakh et al. 1998a, b; Møller et al. 2005b), apparently because of effects of maternal exposure on the ability of their offspring to absorb, metabolize or use antioxidants (Neyfakh et al. 1998a, b). Furthermore, betacarotene supplementation to humans exposed to radiation has been demonstrated to reduce the negative effects of
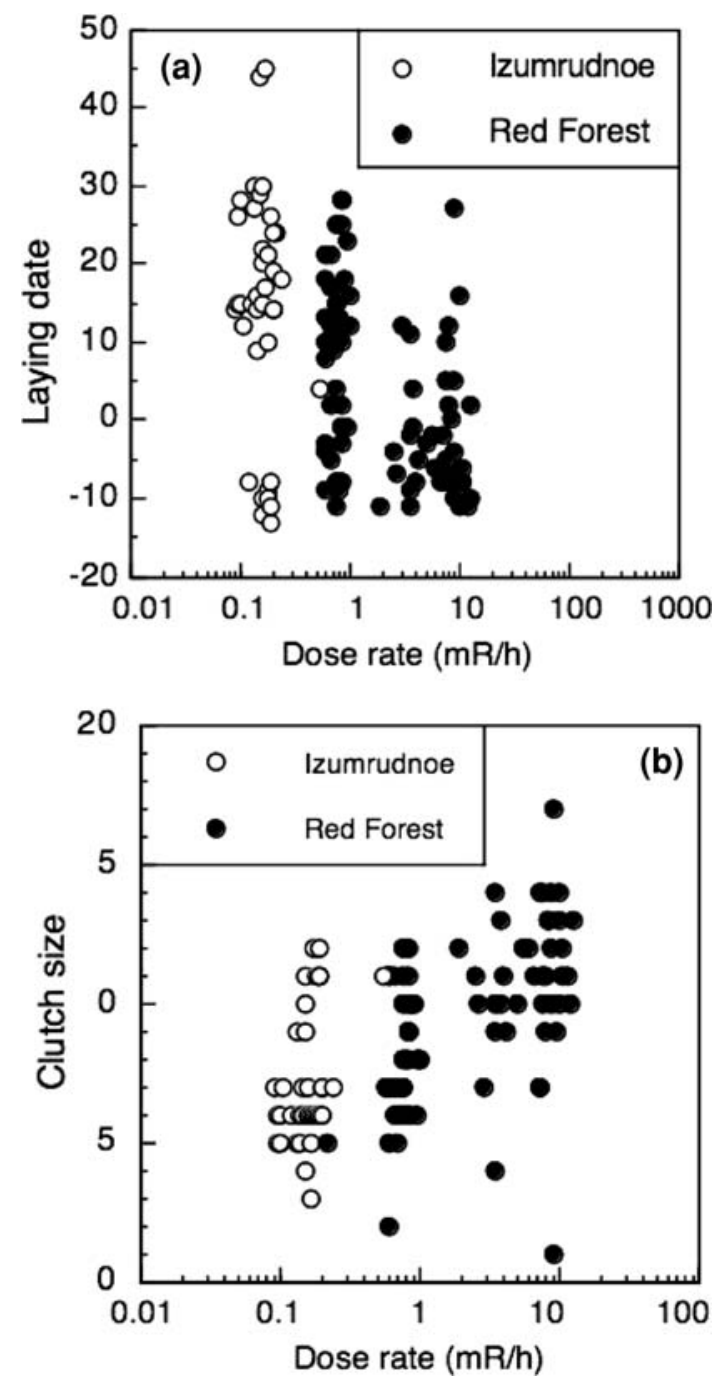

Fig. 2 a Laying date (1 = 1 May) and b clutch size of great tits in relation to dose rate $(\mathrm{mR} / \mathrm{h})$

radiation (Ben-Amotz et al. 1998). Here we have shown large differences among populations in antioxidant levels of yolks of a resident bird species, the great tit, with the lowest levels occurring in the most contaminated parts of the Red Forest. Furthermore, we have shown dose-dependent, negative relationships between levels of background radiation and concentrations in yolks of total carotenoids and vitamins A and E, respectively. This effect of radiation on dietary antioxidants implies that radiation dose will also increase free radical production in developing offspring, further exacerbating the effects of already low levels of antioxidants of maternal origin deposited in eggs. These findings have similarities with those reported for humans by Neyfakh et al. (1998a), who showed that vitamins A and $\mathrm{E}$ were reduced in children in direct proportion to the exposure of their mothers to radiation in the surroundings of Chernobyl, while their own exposure was not important. 


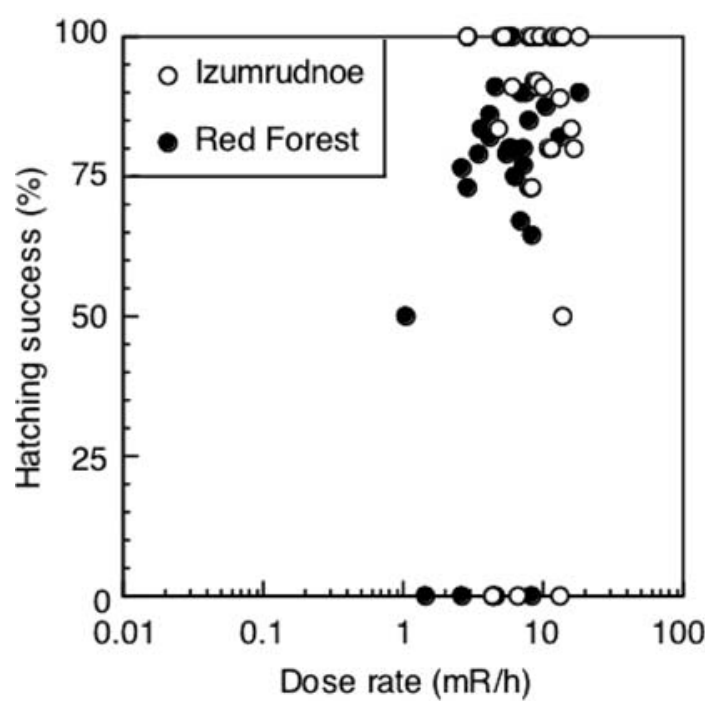

Fig. 3 Hatching success (\%) in relation to dose rates for nest boxes $(\mathrm{mR} / \mathrm{h})$ of great tits. Habitat features, year and study area never entered as significant predictors

We can exclude the possibility that storage under oxygen in a freezer have changed the relationships because of oxidation of samples, because we found no evidence of significant effects of year (and hence duration of storage) on levels of antioxidants.

We analyzed relationships between fitness components (laying date and clutch size) and dose rate and antioxidants. Clutch size increased with background radiation level, while the relationship for laying date was less pronounced. In contrast, there was no significant effect of antioxidant concentrations in yolks on clutch size or laying date, despite the fact that experimental evidence from gulls suggests that clutch size may be limited by carotenoid availability (Blount et al. 2003). We interpret these relationships as indicative of females being exposed to high dose rates increasing their terminal investment in reproduction (Clutton-Brock 1984; Pärt et al. 1992) because of their reduced residual reproductive value. Møller et al. (2005a) showed that adult survival rate for the barn swallow is severely depressed in Chernobyl compared to a control study area. When we investigated hatching and fledging success in relation to dose rate and antioxidant levels, the relationships for dose rate were weak and non-significant, while hatching success increased with increasing concentration of vitamin E. A possible interpretation of the latter result is that embryo mortality increased as the concentration of vitamin $\mathrm{E}$ was reduced, producing the positive relationship between hatching success and vitamin E. Alternatively, the effects of dose rate may cause hatching failure due to elevated mutation rates. However, this explanation is unlikely because vitamin $\mathrm{E}$ rather than dose rate predicted hatching success. We can exclude the possibility that reduced insect abundance in contaminated areas was the underlying mechanism, because we should then not have found increased clutch size and we should have found increased nestling mortality in more contaminated areas. That was not the case (see also Møller and Mousseau 2007a).

Alternative interpretations must be considered because this is a correlational study that does not allow inferences about causation. Hence both directions of causality, as well as indirect effects through third variables, must be entertained. Here we have argued that elevated levels of background radiation reduced concentrations of antioxidants in eggs by affecting antioxidant levels in the females that produced the eggs. However, it is also possible that reduced levels of antioxidants are a cause of negative effects of radioactive contamination of birds by increasing mutation rates. We suggest tentatively that the effect of vitamin $\mathrm{E}$ may outweigh the effect of dose rate on hatching success because it lowers the mutation rate. We tested for effects of habitat features, study area and year on antioxidant levels in yolks, but found no evidence consistent with the explanation that antioxidant levels in yolks could be accounted for by the effects of habitat features, study area or year. We cannot think of any alternative interpretation through third variables that can have produced the negative relationships between antioxidant levels and radiation, although this possibility that the negative relationship between antioxidant levels and radiation was produced by a third variable cannot be excluded. We found strong population differences in antioxidant levels among great tits from the Red Forest, a less contaminated study area in Izumrudnoe and a French control study area, with the less contaminated Ukrainian study area having intermediate levels of antioxidants. The levels of antioxidants recorded for the Chernobyl population are well below what is commonly reported for any bird species (review in Biard 2004). We have previously reported a similarly depressed level of total carotenoids and vitamins $\mathrm{A}$ and $\mathrm{E}$ in the migratory barn swallow (Møller et al. 2005b), suggesting that populations of birds from the Chernobyl Exclusion Zone have peculiar antioxidant status that distinguish them from other populations. This difference may be due to radioactive contamination. The findings reported here occurred despite extensive dispersal in great tits (Paradis et al. 1998), potentially causing Chernobyl populations to be sinks with a net immigration to maintain breeding populations (Møller et al. 2006). Several bird species including the great tit with reduced breeding population density due to radioactivity in the most contaminated areas near Chernobyl are more often long-distance dispersers than expected by chance, suggesting that long-distance dispersal may exacerbate the negative effects of radiation on population density, and that immigration cannot compensate for the negative effects of radiation on local population density (Møller and Mousseau 2007b). 
Although we were able to analyze the effects of radiation only during breeding, fecundity, breeding success and yolk contents, we can speculate about the potential fitness consequences of these documented effects. First, there might be consequences for parents. Elevated clutch size and indications of early start of reproduction in highly contaminated areas are consistent with terminal investment (CluttonBrock 1984; Pärt et al. 1992), and such females may suffer reduced survival and future reproduction. Second, there might be consequences for offspring of depressed pre-natal and neo-natal levels of antioxidants. Previous studies of great tits and chickens suggest that reduced levels of carotenoids in mothers and hence in yolks can have long-lasting effects on the phenotype of offspring (Hõrak et al. 2000; Koutsos et al. 2003). A similar conclusion has been reached for humans, where maternal exposure to radiation reduced levels of vitamins A and E in children (Neyfakh et al. 1998a).

In conclusion, maternal antioxidants were severely depressed in study areas and nest boxes with elevated levels of radiation, in a dose-dependent manner, and clutch size increased with dose rate, while hatching success decreased with concentration of vitamin E. These findings are consistent with the hypothesis that restrictions of antioxidants cause mothers to invest terminally in reproduction, and that reduced levels of antioxidants reduces the viability of embryos as reflected by reduced hatching success.

Acknowledgments We are grateful to S. Gaschak, G. Milinevski, A. M. Peklo, E. Pysanets, I. Chizhevsky, O. Bondarenko, and M. Bondarkov for logistic help during our visits to Ukraine. C. Biard kindly provided information on yolk composition from France. We received funding from the CNRS (France), the University of South Carolina School of the Environment, Bill Murray and the Samuel Freeman Charitable Trust, the Civilian Research Development Foundation, the National Science Foundation and the National Geographic Society to conduct this research.

\section{References}

Alonso-Alvarez C, Bertrand S, Devevey G, Prost J, Faivre B, Sorci G (2004) Increased susceptibility to oxidative stress as a proximate cost of reproduction. Ecol Lett 7:363-368

Barja G, Cadenas S, Rojas C, Perez Campo R, Lopes Torres M (1994) Low mitochondrial free radical production per unit of $\mathrm{O}_{2}$ consumption can explain the simultaneous presence of high longevity and high aerobic rate in birds. Free Radic Res 21:317-318

Bazhan KV (1998) Lipid peroxidation and the antioxidant system in subjects exposed to the influence of extreme factors. Lik Sprava 8:47-50

Ben-Amotz A, Yatziv S, Sela M, Greenberg S, Rachmilevich B, Shwarzman M, Weshler Z (1998) Effect of natural beta-carotene supplementation in children exposed to radiation from the Chernobyl accident. Radiat Environ Biophys 37:187-193

Berthold P (2001) Bird migration. Oxford University Press, Oxford

Biard C (2004) Evolutionary ecology of maternal effects mediated by antioxidants in birds. Laboratoire de Parasitologie Evolutive, Université Pierre et Marie Curie, Paris
Biard C, Surai PF, Møller AP (2006) Carotenoid availability in diet and phenotype of blue and great tit nestlings. J Exp Biol 209:10041015

Biard C, Surai PF, Møller AP (2007) An analysis of pre- and posthatching maternal effects mediated by carotenoids in the blue tit. J Evol Biol 20:326-339

Blount JD, Houston DC, Surai PF, Møller AP (2003) Egg-laying capacity is limited by carotenoid pigment availability in wild gulls Larus fuscus. Proc R Soc Lond B (Biol Lett) 271:S79-S81

Chaialo PP, Bereza VI, Chobot'ko GM (1991) Free-radical processes and blood antioxidant systems in the late period following acute radiation sickness. Med Radiol (Moscow) 36:20-21

Clutton-Brock TH (1984) Reproductive effort and terminal investment. Am Nat 123:212-229

Costantini D, Casagrande S, De Filippis S, Brambilla G, Fanfani A, Tagliavini J, Dell'Omo G (2006) Correlates of oxidative stress in wild kestrel nestlings (Falco tinnunculus). J Comp Physiol B 176:329-337

Costantini D, Fanfani A, Dell'Omo G (2007) Carotenoid availability does not limit the capability of nestling kestrels (Falco tinnuncu$l u s)$ to cope with oxidative stress. J Exp Biol 210:1238-1244

Cramp S, Perrins CM (ed) (1988-1993) The birds of the Western Palearctic. vols 5-7, Oxford University Press, Oxford

Halliwell BH, Gutteridge JMC (1999) Free radicals in biology and medicine. 3rd edn. Oxford University Press, Oxford

Holmes DJ, Flückiger R, Austad SN (2001) Comparative biology of aging in birds: an update. Exp Gerontol 36:869-883

Hõrak P, Vellau H, Ots I, Møller AP (2000) Growth conditions affect carotenoid-based plumage coloration of great tit nestlings. Naturwissenschaften 87:460-464

Hõrak P, Surai PF, Møller AP (2002) Fat-soluble antioxidants in the eggs of great tits Parus major in relation to breeding habitat and laying sequence. Avian Sci 2:123-130

Ivaniota L, Dubchak AS, Tyshchenko VK (1998) Free radical oxidation of lipids and antioxidant system of blood in infertile women in a radioactive environment. Ukr Biokhim Zh 70:132-135

Koutsos EA, Clifford AJ, Calvert CC, Klasing KC (2003) Maternal carotenoid status modifies the incorporation of dietary carotenoids into immune tissues of growing chickens (Gallus gallus domesticus). J Nutr 133:1132-1138

Kumerova AO, Lece AG, Skesters AP, Orlikov GA, Seleznev JV, Rainsford KD (2000) Antioxidant defense and trace element imbalance in patients with postradiation syndrome: first report on phase I studies. Biol Trace Elem Res 77:1-12

Leffler JE (1993) An introduction to free radicals. Wiley, New York

Lykholat EA, Chernaya VI (1999) Parameters of peroxidation and proteolysis in the organism of the liquidators of Chernobyl accident consequences. Ukr Biokhim Zh 71:82-85

Møller AP, Mousseau TA (2007a) Birds prefer to breed in sites with low radioactivity in Chernobyl. Proc R Soc Lond B 274:1443-1448

Møller AP, Mousseau TA (2007b) Determinants of interspecific variation in population declines of birds from exposure to radiation at Chernobyl. J Appl Ecol 44:909-919

Møller AP, Biard C, Blount JD, Houston DC, Ninni P, Saino N, Surai PF (2000) Carotenoid-dependant signals: indicators of foraging efficiency, immunocompetence or detoxification ability? Avian Poult Biol Rev 11:137-159

Møller AP, Mousseau TA, Milinevski G, Peklo A, Pysanets E, Szép T (2005a) Condition, reproduction and survival of barn swallows from Chernobyl. J Anim Ecol 74:1102-1111

Møller AP, Surai PF, Mousseau TA (2005b) Antioxidants, radiation and mutation in barn swallows from Chernobyl. Proc R Soc Lond B 272:247-53

Møller AP, Hobson KA, Mousseau TA, Peklo AM (2006) Chernobyl as a population sink for barn swallows: tracking dispersal using stable isotope profiles. Ecol Appl 16:1696-1705 
Mousseau TA, Fox CW (eds) (1998) Maternal effects as adaptations. Oxford University Press, Oxford

Neyfakh EA, Alimbekova AI, Ivanenko GF (1998a) Vitamin E and A deficiencies in children correlate with Chernobyl radiation loads of their mothers. Biochemistry (Mosc) 63:1138-1143

Neyfakh EA, Alimbekova AI, Ivanenko GF (1998b) Radiation-induced lipoperoxidative stress in children coupled with deficit of essential antioxidants. Biochemistry (Mosc) 63:977-987

Paradis E, Baillie SR, Sutherland WJ, Gregory RD (1998) Patterns of natal and breeding dispersal in birds. J Anim Ecol 67:518-536

Pärt T, Gustafsson L, Moreno J (1992) Terminal investment and a sexual conflict in the collared flycatcher (Ficedula albicollis). Am Nat 140:868-882
Perrins CM (1979) British tits. Collins, London

Saino N, Ferrari RP, Romano M, Martinelli R, Møller AP (2003) Experimental manipulation of egg carotenoids affects immunity of barn swallow nestlings. Proc R Soc Lond B 270:2485-2489

Shestopalov VM (1996) Atlas of Chernobyl exclusion zone. Ukrainian Academy of Science, Kiev

Surai PF (2000) Effect of selenium and vitamin E content of the maternal diet on the antioxidant system of the yolk and the developing chick. Br Poult Sci 41:235-243

Surai PF (2002) Natural antioxidants in avian nutrition and reproduction. Nottingham University Press, Nottingham 